\title{
The immunological and psychological effects of bereavement: does grief counseling really make a difference? A pilot study
}

\author{
Ellen E. Beem ${ }^{\mathrm{c}, *}$, Herbert Hooijkaas ${ }^{\mathrm{b}}$, Marc H.P.D. Cleiren ${ }^{\mathrm{c}}$, Henk A.W. \\ Schut $^{\mathrm{d}}$, Bert Garssen ${ }^{\text {a }}$, Marcel A. Croon ${ }^{\mathrm{e}}$, Lea Jabaaij ${ }^{ }$, Karl Goodkin ${ }^{\mathrm{g}}$, \\ Henk Wind ${ }^{\mathrm{b}}$, Marco J. de Vries ${ }^{\mathrm{a}}$ \\ ${ }^{a}$ Helen Dowling Institute, Rotterdam, The Netherlands \\ ${ }^{b}$ Erasmus University, Rotterdam, The Netherlands \\ ${ }^{\mathrm{c}}$ Leiden University, Leiden, The Netherlands \\ ${ }^{\mathrm{d}}$ Utrecht University, Utrecht, The Netherlands \\ ${ }^{\mathrm{e}}$ Catholic University Brabant, Tilburg, The Netherlands \\ ${ }^{\mathrm{f}}$ Trimbos Institute, Netherlands Institute of Mental Health and Addiction, Utrecht, The Netherlands \\ ${ }^{g}$ University of Miami School of Medicine, Miami, FL, USA
}

\begin{abstract}
This study evaluates psychological and immunological functioning after bereavement and the influence of group counseling. Eighteen widows (bereaved within 3 months of enrolment) and a reference group of 10 married control subjects were asked to fill in self-report scales and to donate a blood sample (T1). After T1, half of the widows (the experimental group) were randomly assigned to grief counseling ( 13 sessions over 4 months), while the other subjects (the control group) received no treatment. Seven months after bereavement (T2) or, in the case of the experimental group, immediately after the intervention, a follow-up was conducted in the widowed subsample using the same measures. Blood samples were analyzed to determine the total number of white blood cells, number of lymphocyte subsets, natural killer cell activity (NKCA) and lymphocyte proliferative response to phytohemagglutinin (PIIA), anti-CD3 and pokeweed mitogen (PWM). At T1, we found significant differences between widows and non-widows regarding both psychological and immunological measures. Widows felt more anxious, depressed, hostile and agoraphobic. At T1, widows had a lower number of the $\mathrm{CD} 19^{+} \mathrm{CD}^{+} \mathrm{B}$ cell subpopulation. The cell function tests for $\mathrm{T}$ and $\mathrm{B}$ cells showed higher responses in widows (lymphocyte proliferation response to PHA, anti-CD3 and PWM). No significant difference in NKCA was found between widows and non-widows. At T2, there appeared to be no significant difference between widows and non-widows on the psychological measures. With respect to the immunological measures, widows and non-widows showed no significant differences for the total number of white blood cells, number of lymphocyte subsets and NKCA. Consistent with our findings at T1, the lymphocyte
\end{abstract}

\footnotetext{
${ }^{*}$ Corresponding author, Department of Social Science, Leiden University, Clinical and Health Psychology, P.O. Box 9555, 2300 RB Leiden, The Netherlands. e-mail: ebeem@rulfsw.leidenuniv.nl
} 
proliferation response to PHA, anti-CD3 and PWM at T2 appeared to be higher in widows than in non-widows. Comparing the experimental group (widows) and the control group (widows) with respect to psychological measures at $\mathrm{T} 1$, widows in the experimental group felt more insufficient and had more sleep disturbances. With respect to the immunological measures, no differences were found between those two groups. When the same two groups were again compared at T2, no differences were found in any of the psychological or immunological measures (lymphocyte sub-populations, proliferation tests and the NKCA). (C) 1999 Elsevier Science Ireland Ltd. All rights reserved.

Keywords: NKCA; T cell; B cell

\section{Introduction}

Bereavement is known as a severe life stressor with psychological and immunological consequences (Murrell et al., 1988; Spurrell and Creed, 1993). Epidemiologic research has demonstrated that persons show increased morbidity and morLality after the death of a family member (Mor et al., 1986; Jones, 1987; McCrae and Costa, 1988; Schaefer et al., 1995; Kissane et al., 1996). Although the psychological consequences of bereavement have been extensively studied, there is still limited knowledge of the impact on immunological functioning. Bereaved people show a decrease in $\mathrm{T}$ and $\mathrm{B}$ cell proliferation (Bartrop ct al., 1977; Schleifer et al., 1983). More recent studies suggest a suppression of natural killer cell activity (NKCA) in bereaved people (Irwin et al., 1987a,b, 1988), but no change in number of natural killer (NK) cells (Pettingale et al., 1994). Zisook et al. (1994b) also neither found a significant difference for number of lymphocytes and number of NK cells for widows vs. a group of non-widowed women nor a difference for NKCA or mitogen stimulation with concanavalin A (ConA). However, a subset of widows with a diagnosis of 'major depressive disorder' (MDD) showed a decreased mitogen stimulation and a decreased NKCA compared to widows without this diagnosis.

Studies on samples of non-bereaved people, focusing on the interaction between clinical depression and NKCA, gave inconsistent results (Stein et al., 1991). Low levels of NKCA in MDD were reported by Urch et al. (1988), Nerozzi et al. (1989) and Maes et al. (1992). However, other researchers did not find a decreased NKCA in MDD. Schleifer et al. (1989) reported no signifi- cant differences between NKCA in 91 patients with unipolar MDD and 91 matched control subjects. Miller et al. (1991) also found no immunological differences, with the exception of an improvement of NKCA for depressed females. Birmaher et al. (1994), likewise, found no significant differences in NKCA for adolescents with or without MDD, but adolescents with MDD having experienced adverse life events showed a lower NKCA compared to adolcscents with MDD without adverse life events.

Several studies (Zisook and Schuchter, 1993, Zisook et al., 1994a; Mendes de Leon et al., 1994) revealed that 1-2 years after the loss of the spouse approximately $15-28 \%$ of bereaved people still show depressive complaints. In the first 2 years of bereavement, Zisook et al. (1994b) even found subsyndromal symptomatic depression associated with substantial morbidity. Studies have been done to assess the effect of supportive programs for bereaved people on psychological and physiological functioning. The nature of these programs varied from the provision of emotional support and practical assistance (Vachon et al., 1980) and self-help groups (Lieberman and Videka-Sherman, 1986; Marmar et al., 1988; Lund et al., 1989; Quarmby, 1993) through to professional-guided grief counseling (Raphael, 1977; Parkes, 1981; Raphael, 1980, 1983; Marmar et al., 1988; Lieberman, 1989; Lieberman and Yalom, 1992). Although these studies had different designs and intervention strategies, one may conclude in general that grief counseling can be a factor in reducing psychological distress. Since the operationalization of the physiological functioning of bereaved people in the aforementioned studies focuses on the increased presence of so- 
matic complaints and/or medical consumption, immunological functioning may be regarded as being of interest as an objective measure of physiological functioning.

With respect to the interaction between psychological and immunological functioning in bereavement, previous research has not produced entirely consistent findings. Although the aforementioned studies on bereavement generally show a suppressive effect on cell functioning tests, the mediating psychological variables between bereavement and immunity remain unclear. In the present pilot study, we compared psychological symptoms and the number and function of $\mathrm{T}, \mathrm{B}$ and NK cells in widows and non-widows. The immunosuppressive effects of bereavement are expected to be most acute in the months immediately following the loss. For this reason, we collected our data as soon as possible ( 3 months after bereavement), restricted only by the guidelines of our medical ethical board. It has been suggested that in non-bereaved people feelings of being in control and of assertiveness and optimism enhance immunological functioning (Rodin and Salovey, 1989; Taylor, 1990). Against this background, we hypothesized that widows would benefit from group counseling in terms of psychological and immunological functioning. In order to address this issue, we assessed the short-term effects of group counseling on psychological and immunological parameters using a randomized, no-treatment control group design.

\section{Methods}

\subsection{Participants}

The following inclusion criteria have been used for all participating women: raised in the Dutch culture, speaking Dutch as native language, having an age of 50-65 years and being physically and psychologically able to cooperate in this study. With respect to the widows, they were widowed for 3 months and had to have lost their spouse after a period of a minimum of 1 week, being in a life-threatening situation. The group of non- widowed, married women were to consist of women living in the same district and were matched for education and employment. Names and addresses of widows who might meet the inclusion criteria were obtained from records of deaths held at the registry office in Rotterdam. Selection was based on the date of bereavement and the age of the deceased. A total of 100 widows were contacted 2 months after bereavement by means of a letter informing them about the study and inviting them to participate. Approximately 1 week later, each of the widows was phoned and asked for her response. If this was positive, an appointment was made for an intake interview. If it then appeared during intake that the widow satisfied the inclusion criteria and was willing to participate, her informed consent was obtained and an appointment was made for the initial tests. A sample of 73 non-widowed married women were approached in the same way.

Many widows $(N=52)$ could not be contacted, either because they had no telephone or an exdirectory number, or because they were staying temporarily with close relatives. Most of these women failed to respond to a 'reminder' letter or responded too late to meet the inclusion criteria. Of the remaining 48 widows, seven were excluded because of the circumstances of their bereavement (a sudden loss caused by, e.g., a heart attack or traffic accident) and three were prevented from participating by their extremely poor physical condition. Of the remaining 38 widows who met the inclusion criteria, 19 refused to participate for various reasons - 'want to cope by myself' ( $N=$ $1)$; 'too confrontational' ( $N=2)$; 'no time' ( $N=$ 1); 'waiting for an opcration' $(N=3)$; 'reluctance to give blood samples' $(N=2)$; 'don't want to be a research object' $(N=2)$; 'already participating in another research project' $(N=4)$ - and four refused to participate without giving any reason. Nineteen appointments were made for intake interviews and the first tests. Eighteen widows completed the study. Of the 73 non-widowed women approached by letter, most could not be contacted by phone (e.g. 'out at work') and only 10 eventually completed the study (the reference group). 


\subsection{Study design}

Eighteen widows who had been bereaved 3 months ago and a reference group of 10 married control subjects were asked to fill in self-report scales and to donate a blood sample (T1). After $\mathrm{T} 1$, half of the widows were randomly assigned to grief counseling (13 sessions over 4 months), while the other subjects received no treatment. Seven months after bereavement (T2) or, in case of the experimental group, immediately after the intervention, a follow-up was conducted in the widowed subsample using the same measures (Fig. 1). Blood samples were analyzed with regard to total absolute number of white blood cells, absolute number of several lymphocyte subsets $\left[\mathrm{CD} 19^{+}\right.$; $\mathrm{CD}_{19}{ }^{+} \mathrm{CD}^{+}{ }^{+} \mathrm{CD}^{+}$; $\mathrm{CD}^{+}{ }^{+} \mathrm{CD} 3^{+}$; $\mathrm{CD}^{+}{ }^{+} \mathrm{CD} 3^{+}$; $\mathrm{CD}^{+}{ }^{+} \mathrm{HLA} \mathrm{DR}^{+}$(CD16 and/or CD56 ${ }^{+}$) $\mathrm{CD}^{-}$], natural killer cell activity, and lymphocyte proliferative response to PHA, anti-CD3 and PWM.

\subsection{Psychological data}

Psychological symptoms were assessed using the SCL-90 self-report scale (Arrindell and Ettema, 1981). This 90 -item scale asks about symptoms which have occurred during the preceding week and consists of eight sub-scales: agoraphobia, anxiety, somatic symptoms, depression, distrust and interpersonal sensitivity, insufficiency, hostility and sleep disturbances. The intensity is rated on a five-point scale (ranging from 'not at all' to 'extremely').

\subsection{Immunological data}

Phenotyping of the following subsets of lymphocytes was performed by incubating $100 \mu \mathrm{l}$ of whole heparinized blood with (combinations of) conjugated monoclonal antibodies. Natural killer cell activity was measured and proliferation tests were performed by stimulating peripheral blood mononuclear cells (PBMC) with PHA, anti-CD3, and PWM.

\subsubsection{Procedure for collecting blood}

Between 09.00 and $11.30 \mathrm{~h}, 60 \mathrm{ml}$ of peripheral blood (PB) was obtained using 10-ml Na-heparin coated tubes. The blood samples were taken from the median cubital vein of the forearm with a vacuum system. All analyses were performed the same day as the samples were collected.

\subsubsection{Phenotyping of peripheral blood mononuclear cells (PBMC)}

Leukocytes were phenotyped using a FACScan flow cytometer (Becton Dickinson, San Jose, CA, USA). Whole blood was incubated with a panel of optimally titrated fluorescein isothiocyanate (FITC) or phycoerythrin (PE) conjugated monoclonal antibodies (Moabs) for single or multiple immunofluorescence staining. Irrelevant IgG2 FITC or IgG1 PE conjugated Moabs were used as negative controls. Before determination of the percentage of positive cells, red blood cells were lysed using FACS Lysing Solution (Becton Dickinson). The Moabs used in this study were ob-

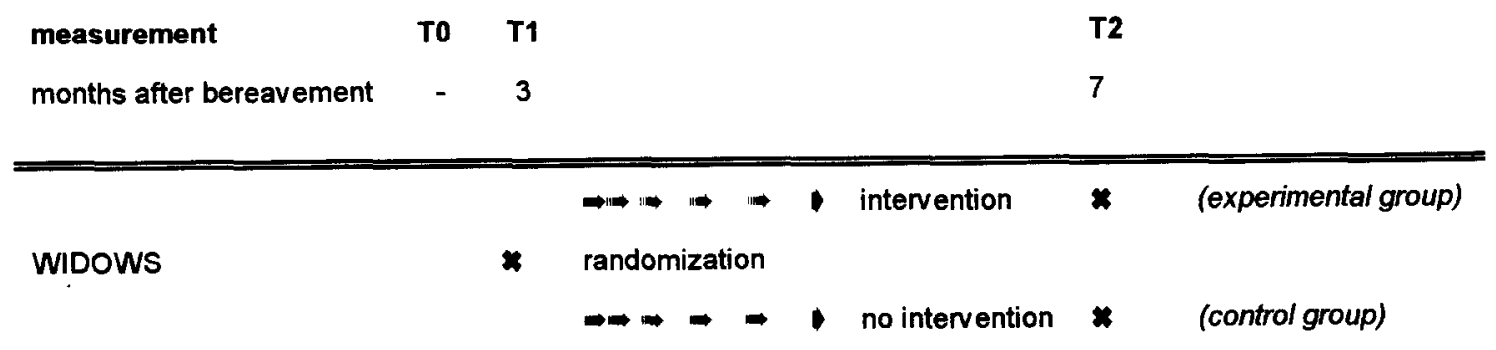

Fig. 1. Visual representation of study design. 
tained from Becton Dickinson, unless otherwise stated, and were: CD19 (Leu-12 PE) and CD20 (B1 FITC; Coulter Clone, Hialeah, FL, USA) to label B cells; CD3 (Leu-4 FITC), CD4 (Leu-3 FITC or Leu-3 PE) and CD8 (Leu-2 PE) to label T cells; CD5 (Leu-1 FITC) to label T and B cells; CD16 (Leu-11c PE) and CD56 (Leu-19 PE) to label NK cells; anti-HLA-DR (L243 PE) to label activated T cells; and CD14 (My4 PE; Coulter Clone) and CD45 (HLe-1 FITC) to determine, in combination with the whole bloud forward and side-scatter patterns, the percentages of granulocytes, monocytes and lymphocytes (Leucogate). Further data analyses were performed on the lymphocyte population thus defined. This lymphocyte population represented at least $95 \%$ of the total number of lymphocytes and contained $<3 \%$ contamination by monocytes. White blood cell counts were performed using a Coulter Counter Model ZM (Coulter Electronics, Hialeah, FL, USA). In this way, percentages as well as absolute numbers of the following lymphocyte (sub)populations were determined: B lymphocytes (CD19 ${ }^{+}$ and/or $\mathrm{CD}_{20}{ }^{+}$); $\mathrm{CD}^{+} \mathrm{B}$ lymphocytes $\left(\mathrm{CD}^{+}\right.$, $\left.\mathrm{CD} 19^{+}\right)$; $\mathrm{CD}^{+} \mathrm{T}$ lymphocytes $\left(\mathrm{CD} 4^{+}, \mathrm{CD}^{+}\right)$; $\mathrm{CD}^{+} \mathrm{T}$ lymphocytes $\left(\mathrm{CD} 8^{+}, \mathrm{CD}^{+}\right)$; activated $\mathrm{T}$ lymphocytes (HLA-DR ${ }^{+}, \mathrm{CD}^{+}$); and NK cells $\left(\mathrm{CD} 16^{+}\right.$and $/$or $\left.\mathrm{CD}^{+} 6^{+}, \mathrm{CD}^{-}\right)$.

\subsubsection{Isolation of PBMC}

PBMC were prepared by a standard density gradient separation. Heparinized blood was diluted in the proportion 1:1 with phosphatebuffered saline (PBS; $\mathrm{pH}=7.2$ ), and layered on a Ficoll-Hypaque gradient $\left(d_{20}{ }^{\circ} \mathrm{C}=1.077 \mathrm{~g} / \mathrm{cm}^{3}\right.$; Pharmacia, Sweden). Cells were washed twice in RPMI 1640 culture medium with Hepes, supplemented with L-glutamine $(29.2 \mathrm{~g} / 1)$, penicillin/ streptomycin $(5.99 / 10.0 \mathrm{~g} / \mathrm{l})$ and $10 \%$ heat inactivated FCS. The FCS was specially selected for its growth-supporting properties and low endogenous mitogenic activity.

\subsubsection{NK cell assay}

PBMC were resuspended in $0.5 \mathrm{ml}$ of culture medium with concentrations of $5,2.5,1.2$ and $0.06 \times 10^{6}$. The erythroblastoid NK-sensitive cell line $\mathrm{K} 562$ was used as a target cell line. Vital K562 cells were counted by trypan blue dye exclusion. After labeling $2 \times 10^{6} \mathrm{~K} 562$ cells with 200 $\mu \mathrm{l} \mathrm{Na}{ }^{51} \mathrm{CrO}_{4}$ (3.7 MBq; Amersham, UK) and 100 $\mu$ l culture medium for $1 \mathrm{~h}$ at $37^{\circ} \mathrm{C}, 5 \% \mathrm{CO}_{2}$, the cells were washed twice and resuspended in RPMI 1640 medium (Gibco, USA) supplemented with $5 \%$ heat inactivated FCS. Cultures were set up with four PBMC to target cell $(\mathrm{T})$ ratios by mixing a constant number of ${ }^{51} \mathrm{Cr}$-labeled target cells $\left(0.1 \times 10^{6}\right.$ cells $\left./ \mathrm{ml}\right)$ with four dilutions of PBMC (E). The four E:T ratios are 50:1, 25:1, 12.5:1 and $0.63: 1$. After $4 \mathrm{~h}$ the supernatants were harvested and counted in a gamma counter. The data were expressed in terms of lytic units (LU) $20 \%$, defined as the number of cells required to cause $20 \%$ of target cell lysis.

\subsubsection{Lymphocyte proliferation tests}

In all cell culture experiments, PBMC were adjusted to a final concentration of $5 \times 10^{5}$ cells $/ \mathrm{ml}$. Cells were cultured in the same RPMI 1640 medium used for the isolation of PBMC. The following mitogens were added in optimal concentrations: PHA (100 $\mu \mathrm{g} / \mathrm{ml})$; Wellcome Diagnostics, Dartford, UK), ConA (100 $\mu \mathrm{g} / \mathrm{ml}$; Sigma Chemical Co., St Louis, MO, USA), and PWM $(10 \mu \mathrm{g} / \mathrm{ml}$; Gibco Laboratories, Grand Island, NY, USA). As a control, cells were cultured without mitogens. For the measurement of $\left[{ }^{3} \mathrm{H}\right]$ thymidine incorporation, PBMC were cultured in 96-well flat-bottom tissue culture plates ( $10^{5}$ cells/well; Costar, Cambridge, MA, USA). Incubation was performed at $37^{\circ} \mathrm{C}$, at $100 \%$ relative humidity and at a $\mathrm{PCO}_{2}$ of $5 \%$. PBMC were cultured for 72 and $168 \mathrm{~h}$. The $\left[{ }^{3} \mathrm{H}\right]$ thymidine pulsing was for $6 \mathrm{~h}$; after the 6-h pulse the cells were harvested. The $\left[{ }^{3} \mathrm{H}\right]$ thymidine incorporation was measured in a liquid scintillation counter (Packard, Downers Grove, IL, USA).

\subsection{Intervention}

The intervention consisted of grief counseling in a closed group-setting. Thirteen semi-structured sessions were offered to the 11 widows. The grief counseling group met weekly, with a few exceptions due to holidays, over a period of 4 
months. The first and last sessions took $5 \mathrm{~h}$ : the first to give the participants time to get acquainted, and the last to give the participants time to take proper leave from the group. The other 11 sessions lasted 2 h $30 \mathrm{~min}$. The group was led by two trained counselors, who were supervised throughout the counseling. Sessions were audiotaped with the consent of the participants. The program focused on helping individual widows to find the best possible way to adapt to their new situation. The central elements in this process of adaptation were "rebuilding a new relationship with the deceased' and 'getting in touch with your own needs and feelings' (Yalom and Vinogradov, 1988; Yalom and Lieberman, 1991; Lieberman and Yalom, 1992). Most of the interventions were made at an individual level; they varied from supportive to insight-oriented interventions. Special attention was paid to how to deal with feelings, e.g. the importance of accepting one's own feelings. To help the widows to get in touch with their feelings, the counselors used exercises derived from Gestalt techniques. For instance, the counselors invited the widows to locate 'the grief' within their body, to describe 'the grief', and to ask 'the grief' what it needed. The trained counselors also could make use of guided visualization exercises. These exercises required a safe group climate and a check for the resilience of each group member.

\subsection{Statistical analyses}

Student's $t$-tests ( $t$-tests) were used to compare at $\mathrm{T} 1$ and $\mathrm{T} 2$ the psychological and immunological data of the widows with those of the reference group, and to compare at $\mathrm{T} 1$ (baseline) those of the experimental group with the control group. Since we were interested in separate outcome variables and the sample did not allow for extensive MANOVAs, we performed separate ANCOVAs for each of the psychological - and immunological - variables. In a pre-step, we examined whether the design had to be controlled for expectedness of death, period of illness and age of the widows (entered as co-variates) by checking the Pearson correations between these and the outcome variables. Data at $\mathrm{T} 2$ from the experimental and control groups of widows were tested using ANCOVAs, with the T1 level as the covariate (and if appropriate: expectedness of death, period of illness and age of the widows). Significance level was set at $P=0.05$.

\section{Results}

\subsection{Characteristics of the participants}

The sample comprised 18 widows ranging in age between 45 and 64 years (mean 58.6 years; S.D. 4.9) and 10 non-widows aged from 49 to 70 years (mean 58.9 years; S.D. 6.5). Among the widows, five were educated to high school level or beyond, 12 were unemployed and eight had a net family income at or below the national average. In the non-widowed group, five women were educated to high school level or beyond, seven were unemployed and three had a net family income at or below the national average.

\subsection{Psychological findings}

At $\mathrm{T} 1$ (one-tailed) $t$-tests revealed significant differences in sevcral psychological variables between the widows (the experimental and the control groups) and the non-widows (the reference group). The widows felt more anxious, more depressed, more hostile and more agoraphobic than the non-widows. No significant differences were found for the SCL-90 scales: somatic symptoms, interpersonal sensitivity, insufficiency and sleep disturbances (Table 1). Unlike the immunological variables presented later, the psychological measures showed unequal within-group variances. In view of the fact that these scales measure complaints where bottom effects apply in normal populations, this was to be expected. Since this may result in equal variances between experimental and control groups, Levene's test for unequal variances was applied. Baseline differences were found between the experimental and control groups of widows as regards insufficiency $(t=2.25$; d.f. $=16 ; P=0.02)$ and sleep disturbances $(t=$ 2.39 ; d.f. $=14 ; P=0.02$ ). Despite the randomization, the widows in the experimental group felt more insufficient and had more sleep disturbances than those in the control group. 
Table 1

SCL-90: widows at $\mathrm{T} 1$ and $\mathrm{T} 2$ compared to non-widows at $\mathrm{IO}$

\begin{tabular}{|c|c|c|c|c|c|}
\hline \multirow[t]{2}{*}{ SCL-90 } & \multirow{2}{*}{$\begin{array}{l}\text { T0 } \\
\text { Non-widow }\end{array}$} & \multicolumn{2}{|l|}{ T1 } & \multicolumn{2}{|l|}{$\mathrm{T} 2$} \\
\hline & & Widows $^{\mathrm{a}}$ & $t$-value ${ }^{b c}$ & Widows $^{\text {a }}$ & $t$-value $\mathrm{e}^{\mathrm{b} d}$ \\
\hline Anxiety & $13(2.6)$ & $17(5.2)$ & $-2.16^{*}$ & $16(6.4)$ & 1.18 \\
\hline Agoraphobic behavior & $7(1.0)$ & $8(2.1)$ & $-1.89^{*}$ & $8(1.5)$ & 1.03 \\
\hline Depression & $23(6.5)$ & $30(8.7)$ & $-2.55^{*}$ & $26(7.5)$ & 1.23 \\
\hline Somatisation & $19(5.5)$ & $21(6.0)$ & -0.90 & $19(4.5)$ & 0.17 \\
\hline Insufficiency & $15(4.4)$ & $17(5.8)$ & -0.73 & $15(6.0)$ & -0.04 \\
\hline Interpersonal sensitivity & $24(5.1)$ & $26(7.4)$ & -0.98 & $25(8.7)$ & 0.43 \\
\hline Hostility & $7(0.7)$ & $8(2.3)$ & $-2.01^{*}$ & $7(1.2)$ & 1.08 \\
\hline Sleep disturbances & $8(2.6)$ & $7(3.6)$ & 0.52 & $7(3.9)$ & -0.20 \\
\hline
\end{tabular}

${ }^{a}$ Data are expressed as the mean with S.D. in parenthescs; widows $(N=18)$, non-widows $(N=10)$. The non-widows are the reference group.

${ }^{\mathrm{b}}$-tests are performed (one-tailed); ${ }^{*} P \leq 0.05$.

${ }^{\mathrm{c}}$ Fractional d.f. values are computed and ranged between 20.8 and 26.0 .

${ }^{\mathrm{d}}$ Fractional d.f. values are computed and ranged between 16.4 and 26.0.

Seven months after the loss, the mean scores for anxiety, agoraphobic behavior, depression, somatisation, insufficiency, interpersonal sensitivity and hostility were decreased. No changes in the mean scores in widows were found for agoraphobic behavior and sleep disturbances. Comparing the psychological measures of the widows at T2 with the non-widows, there appeared to be no significant differences.

In a pre-step, we examined whether, with respect to psychological variables, the design had to be controlled for expectedness of death, period of illness and age of the widow by checking the Pearson correlation between these variables and each psychological outcome variable. This only showed a significant correlation between period of illness and the interpersonal sensitivity and insufficiency subscales of the SCL-90. Because of these findings, they were not evaluated in the subsequent analyses of covariance that examined the intervention effect, with the exception of the analyses for the interpersonal sensitivity and insufficiency scales.

In a series of ANCOVA analyses, the SCL-90 subscales for depression, agoraphobia, anxiety, somatic symptoms, hostility and sleep disturbances were examined at $\mathrm{T} 2$, with $\mathrm{T} 1$ as a covariate to control for baseline differences between groups. For none of these psychological variables, intervention effects were found for the grief counseling group. In the remaining analyses (for the sensitivity and insufficiency scales) illness period was added as a covariate to the equation. In neither of these was there a statistically significant contribution of the covariates, and also here no intervention effect was found.

\subsection{Immunological findings (number of peripheral blood lymphocyte subpopulations)}

At T1, $t$-tests were used to compare the number of lymphocyte subpopulations in widows and non-widows (Table 2). These tests revealed a significantly lower absolute number of $\mathrm{CD} 19^{+} \mathrm{CD} 5^{+}$ $B$ lymphocytes in the widows. No differences in absolute numbers of lymphocytes, monocytes and granulocytes could be demonstrated between the widows and non-widows (Table 3). Comparison of the experimental and the control group of widows at baseline (T1) revealed no significant differences.

Comparing the mean scores of the number of lymphocyte subpopulations, the absolute numbers of lymphocytes, monocytes and granulocytes in the widows at $\mathrm{T} 2$ with the non-widows revealed no significant differences.

At $\mathrm{T} 2$, in a pre-step, we examined whether the design had to be controlled for expectedness of 
Table 2

Peripheral blood lymphocytes: widows at $\mathrm{T} 1$ and $\mathrm{T} 2$ compared to non-widows at $\mathrm{T} 0$

\begin{tabular}{|c|c|c|c|c|c|c|}
\hline \multirow{2}{*}{$\begin{array}{l}\text { Lymphocyte } \\
\text { subpopulations }\end{array}$} & \multirow[t]{2}{*}{ Markers } & \multirow{2}{*}{$\begin{array}{l}\text { T0 } \\
\text { Non-widows }\end{array}$} & \multicolumn{2}{|l|}{$\mathrm{T} 1$} & \multicolumn{2}{|l|}{$\mathrm{T} 2$} \\
\hline & & & Widows $^{\mathrm{a}}$ & $t$-value ${ }^{b c}$ & Widows $^{a}$ & $t$-value ${ }^{b d}$ \\
\hline $\mathbf{B}$ & CD19 ${ }^{+}$ & $0.27(0.4)$ & $0.27(0.4)$ & -1.11 & $0.19(0.1)$ & -1.62 \\
\hline B CD5 & $\mathrm{CD} 19^{+} \mathrm{CD}^{+}$ & $0.07(0.1)$ & $0.06(0.1)$ & $-2.30^{*}$ & $0.03(0.0)$ & -3.01 \\
\hline $\mathrm{T}$ & $\mathrm{CD}^{+}$ & $1.26(0.5)$ & $1.13(0.5)$ & -0.75 & $1.35(0.5)$ & 0.52 \\
\hline T CD4 & $\mathrm{CD}^{+}{ }^{+} \mathrm{CD}^{+}{ }^{+}$ & $0.75(0.4)$ & $0.86(0.4)$ & 1.11 & $0.90(0.4)$ & 1.38 \\
\hline T CD8 & $\mathrm{CD} 8^{+} \mathrm{CD} 3^{+}$ & $0.37(0.3)$ & $0.37(0.3)$ & -0.17 & $0.33(0.2)$ & -0.32 \\
\hline T HLA-DR & $\mathrm{CD}^{+}{ }^{+} \mathrm{HLA} \mathrm{DR}{ }^{+}$ & $0.14(0.4)$ & $0.20(0.1)$ & 0.11 & $0.12(0.0)$ & -0.08 \\
\hline $\mathrm{NK}$ & $\begin{array}{l}(\mathrm{CD} 16 \text { and } / \text { or } \mathrm{CD} 56)^{+} \\
\mathrm{CD}^{-}\end{array}$ & $0.19(0.1)$ & $0.15(0.1)$ & -1.24 & $0.17(0.1)$ & -0.86 \\
\hline
\end{tabular}

${ }^{a}$ Data are expressed as the mean of the number of $\left(N \times 10^{9}\right)$ lymphocytes $/ 1$ with S.D. in parenthescs; widows $(N s$ ranged betwecn 16 and 18), non-widows $(N=10)$. The non-widows are the reference group.

${ }^{b} t$-tests are performed after a $\log$ transformation (two-tailed); ${ }^{*} P \leq 0.05$.

${ }^{c}$ d.f. $=25.0$.

d.f. values are computed and ranged between 23.0 and 25.0.

death, period of illness and age of the widows by checking the Pearson correlation between these variables and the outcome variable (immunological variables). No significant correlations were found. At T2, using ANCOVAs with $\mathrm{T} 1$ as the single covariate, no significant differences were found between the experimental and the control group for any of the measured lymphocyte subpopulations.

\subsection{Immunological findings (lymphocyte proliferation tests and NK cell assay)}

At $\mathrm{T} 1$, the proliferation tests for $\mathrm{T}$ cells, conducted by stimulating PBMC with PHA and anti-
CD3 for $72 \mathrm{~h}$, revealed a significant difference between the widows and non-widows at T1. After correction for spontaneous proliferation, we found significant differences in PHA and anti-CD3 after $72 \mathrm{~h}$. After $168 \mathrm{~h}$, the PWM-induced B cell proliferation appeared to be increased in the widows, and this difference remained significant after correction for spontaneous proliferation. NKCA measured in lytic units (LU) at T1 showed no significant difference between widows and nonwidows (Table 4). Comparing the experimental and control group of widows at $\mathrm{T} 1$, no significant differences were found in either the lymphocyte proliferation tests or the NK cell assay (Table 4).

With regard to the lymphocyte proliferation

Table 3

Peripheral blood lymphocytes: widows at $\mathrm{T} 1$ and $\mathrm{T} 2$ compared to non-widows at $\mathrm{T} 0$

\begin{tabular}{|c|c|c|c|c|c|}
\hline \multirow[t]{2}{*}{ Leukocytes } & \multirow{2}{*}{$\begin{array}{l}\text { T0 } \\
\text { Non-widows }\end{array}$} & \multicolumn{2}{|l|}{$\mathrm{T} 1$} & \multicolumn{2}{|l|}{$\mathrm{T} 2$} \\
\hline & & Widows $^{\mathrm{a}}$ & $t$-value $\overline{\text { bc }}$ & $\overline{\text { Widows }^{\mathrm{a}}}$ & $t$-value $\mathrm{e}^{\mathrm{bd}}$ \\
\hline Leucocytes & $5.87(1.7)$ & $5.13(1.7)$ & -1.03 & $5.51(1.5)$ & -0.56 \\
\hline Monocytes & $0.32(0.1)$ & $0.33(0.2)$ & 0.12 & $0.39(0.2)$ & 1.13 \\
\hline Granulocytes & $3.77(1.2)$ & $3.16(1.2)$ & -1.25 & $3.25(0.9)$ & -1.20 \\
\hline Lymphocytes & $1.78(0.6)$ & $1.63(0.5)$ & -0.72 & $1.77(0.6)$ & -0.04 \\
\hline
\end{tabular}

${ }^{a}$ Data are expressed as the mean with S.D. in parentheses; widows $(N \mathrm{~s}$ ranged between 16 and 18$)$, non-widows $(N=9)$. The non-widows are the reference group.

${ }^{\mathrm{b}} t$-tests are performed (two-tailed); ${ }^{*} P \leq 0.05$.

${ }^{c}$ d.f. values are computed and ranged between 23.0 and 25.0 .

d d.f. values are computed and ranged between 24.0 and 25.0. 
Table 4

Natural killer cell activity (NKCA) and lymphocyte proliferation response to PWM, PHA and anti-CD3: widows at T1 and T2 compared to non-widows at $\mathrm{TO}$

\begin{tabular}{|c|c|c|c|c|c|}
\hline & \multirow{2}{*}{$\begin{array}{l}\text { T0 } \\
\text { Non-widows }\end{array}$} & \multicolumn{2}{|l|}{$\mathbf{T} 1$} & \multicolumn{2}{|l|}{$\mathrm{T} 2$} \\
\hline & & Widows $^{\mathrm{a}}$ & $t$-value $\mathrm{e}^{\mathrm{bc}}$ & $\overline{\text { Widows }^{\mathrm{a}}}$ & $t$-value $e^{\text {bd }}$ \\
\hline \multicolumn{6}{|l|}{ NKCA: } \\
\hline Lytic units & $16.80(9.8)$ & $12.93(11.0)$ & -0.99 & $14.68(5.8)$ & -0.73 \\
\hline \multicolumn{6}{|c|}{ Lymphocyle proliferation $\left(\mathrm{CPM} \times 10^{3}\right)$ : } \\
\hline PHA (72 h) & $43.66(40.1)$ & $89.41(32.0)$ & $3.30^{* *}$ & $91.22(24.2)$ & $3.42^{* *}$ \\
\hline Anti-CD3 (72 h) & $41.95(20.0)$ & $70.17(26.6)$ & $3.01^{* *}$ & 72.4. (20.3) & $3.90^{* *}$ \\
\hline PWM (168 h) & $34.00(19.2)$ & $63.70(27.4)$ & $3.16^{* *}$ & $64.11(23.6)$ & $3.66^{* *}$ \\
\hline
\end{tabular}

${ }^{a}$ Data are expressed as the mean with S.D. in parentheses; widows ( $N$ s ranged between 17 and 18), non-widows $(N=10)$. The non-widows are the reference group.

${ }^{b} t$-tests are performed (two-tailed); ${ }^{*} P \leq 0.05,{ }^{* *} P \leq 0.01$.

${ }^{c} \mathrm{~d}$.f. values are computed and ranged between 24.0 and 25.0 .

${ }^{d}$ d.f. values are computed and ranged between 25.0 and 26.0 .

response to PHA, anti-CD3 and PWM in widows at $\mathrm{T} 2$, widows showed significant differences compared to non-widows. Consistent with our findings at $\mathrm{T} 1$, the cell function tests for $\mathrm{T}$ and $\mathrm{B}$ cells showed higher responses in widows (lymphocyte proliferation response to PHA, anti-CD3 and PWM). No differences wcre found between the widows, at $\mathrm{T} 2$, and the non-widows for NKCA.

In the same way as was done for the psychological variables, we examined in a pre-step whether the design had to be controlled for expectedness of death, period of illness and age of the widows by checking the Pearson correlation between these variables and immunological outcome variables. In view of the absence of significant correlations, these could be excluded from further analyses of the therapy effect.

At T2, using ANCOVAs with T1 as the single covariate, no significant differences were found between the experimental and the control group either in the lymphocyte proliferation tests or in the NK cell assay.

\section{Discussion}

The purpose of this pilot study was to obtain greater insight into the effects of bereavement on each psychological and immunological variable. We found a relationship between widowhood and feelings of anxiety, depression, hostility and agoraphobia. These findings were to be expected and are consistent with the bereavement literature (Parkes and Brown, 1972; Lund et al., 1986, 1989; Zisook et al., 1990; Zisook and Schuchter, 1991; Stroebe and Stroebe, 1991; Cleiren, 1993; Pettingalc et al., 1994). We found no significant difference between the widows and the nonwidows as regards physical functioning, measured on the subscale 'somatisation' of the SCL-90. This finding is not consistent with previous research (Parkes and Weiss, 1983; Lund et al., 1989). As concerns the influence of the expectedness of death and age of the widows on psychological functioning after bereavement, our findings are consistent with previous research. We found an absence of relation between expectedness of death and psychological functioning (Range and Niss, 1990; Cleiren, 1993) and no evidence that the age of the widow was related to psychological functioning (Cleiren, 1993). Comparing the widows and non-widows at $\mathrm{T} 1$ as regards their white blood cell count (total number of white blood cells, granulocytes, monocytes and lymphocyte subsets), the only difference identified was a significantly lower number of $\mathrm{CD} 19^{+} \mathrm{CD5}^{+} \mathrm{B}$ lymphocytes in the widows. These findings are unexpected: we know from previous research that depression is associated with elevated white blood cell counts (Maes et al., 1992; Seidel et al., 1996), 
and in the present study depression scores were increased in the widows. Recent studies have emphasized the influence of age on white blood cell count (Lehtonen et al., 1990; Sansoni et al., 1993; Pekelharing, 1995), but we were unable to demonstrate such an influence. With respect to the functional measures, significant differences were found at $\mathrm{T} 1$ between widows and non-widows as regards $\mathrm{T}$ and $\mathrm{B}$ cell proliferation, but not in NK cell activity. Seven months after bereavement, widows still evidence increased $T$ and $B$ lymphocyte functioning compared to non-widows. These findings were not consistent with previous studies (Bartrop et al., 1977; Schleifer et al., 1983). The disparity in the findings on post-bereavement lymphocyte proliferation and mitogen might be related to a potential quadratic function with depressed mood level, i.e. there is a decrease at low and high depressed mood levels (Spurrell and Creed, 1993). This might be interacting with an acute activating effect associated with the adoption of an active coping strategy (Goodkin et al., 1992, 1996).

We were not able to support the hypothesis that gricf counscling would enhance the psychological and immunological functioning of the widows. The experimental and control groups differed at $\mathrm{T} 1$ with regard to some psychological variables (insufficiency and sleep disorders). No significant differences were found between the two groups in the baseline values (T1) of any of the immunological variables. When testing for differences between the two groups after counseling (T2), possible differences in the baseline values of any of the variables were taken into account by applying ANCOVAs, using the baseline values of the tested variable as a covariate. No intervention effect (T2) was found in any of the psychological or immunological measures.

Our findings from this comparison of recently bereaved women with married control subjects suggest that the idea that bereavement itself can cause immunosuppression may be open to question. Considering the research on depression and immunological functioning, a possible explanation is that our group of widows were not 'severely' depressed but merely experiencing an increased level of depressive feelings as compared with the
SCL-90 norm group (norm group II, women). The absence of differences between the widows and non-widows with regard to 'somatisation' at T1 is in line with the finding that the widows showed no signs of immunosuppression. With respect to the effect of grief counseling, there are several explanations. The reason for the apparent lack of improvement in psychological functioning might be that we did not select specifically 'high risk' widows for the grief counseling. Some researchers have suggested that a so-called 'high risk' individual (a person at 'high risk' of experiencing a pathological grieving process) may benefit more from counseling than a person without this factor (Parkes, 1975; Raphael, 1977; Vachon et al., 1980; Schut, 1992). The reason for abstaining from any such selection was that it would have interfered with our wish to compare the psychological and immunological functioning of widows and nonwidows. Moreover, while such a criterion may be considered relevant to the psychological outcome, there is no evidence that it may also affect immunological response. One explanation for the lack of any indication of improvement in immunological functioning may be the absence of immunosuppression in the widows at baseline (T1). Another possible explanation is that T2 followed too closely after the final session. The widows in the grief counseling group were made more aware of 'their own feelings' and 'how to deal with these feelings'. It is possible that the grief counseling caused some short-term distress which temporarily diminished the immunological functioning of the widows in the experimental (grief counseling) group. Fawzy et al. (1990) evaluated the immediate and long-term effects on immunological functioning of a structured psychiatric intervention (for patients with malignant melanoma) and found more significant differences in immunological variables between the two groups 6 months after the intervention than immediately after it. Although the subjects in this study differed from ours in that they were not in apparently normal health, the results suggest that the outcome of ours might have been different if the measurements had been taken 6 months after the intervention.

We are aware that our pilot study has several 
limitations. One, which is almost inherent to the character of a pilot study, is the sample size. Another important issue is that we chose to consider the influence of every psychological and immunological variable in its own right on the condition of widows/non-widows. For that reason, we did not correct with the Bonferroni inequality, which clouds real differences between variables when there is a large quantity of dependents. Were Bonferroni criteria to be applied, only the largest differences in $\mathrm{T}$ and $\mathrm{B}$ cell functioning between widows and non-widows at $\mathrm{T} 1$ would remain statistically significant.

In an excellent review, Stein et al. (1991) highlight methodological issues in research studies focusing on depression and immunological functioning. These methodological issues, which circumscribe the generalizability of a number of studies, include diagnostic heterogeneity, sample size, control group composition, and assay techniques. These issues also play an important role in bereavement studies. Bereavement studies differ in terms of the selection of the bereaved (selection by cause of death of the deceased and by age of the participant). Morcover, most bcreavement studies involve small samples of bereaved participants, and some do not include a control group. Apart from the fact that the assay techniques used in the different bereavement studies may influence their results, other technical laboratory issues also need to be taken into account in comparing the results of different studies. These include the blood sampling and cell preparation procedures. Although problems of comparability between bereavement studies were an important reason for performing this pilot study, the same problem also limits the interpretation of our results.

\section{Acknowledgements}

We acknowledge the support of Dutch Ministry of Health grant BGZ no. 121113 and the support of NIMH 1 R-01 MH48628 (USA) (for K. Goodkin, M.D., Ph.D.). We are indebted to Professor S. Maes and Heijnen, C.J., M.D. for their helpful supervision of database construction and management; to E. de Regt and J. de Kler for the provision of grief counseling; to A. Vis for administrative support; and to P. Platenburg for the provision of technical assistance.

\section{References}

Arrindell, W.A., Ettema, H., 1981. Dimensionele structuur, betrouwbaarheid en validiteit van de Nederlandse bewerking van de Symptom Checklist (SCL-90). [Dimensional structure, reliability and validity of the Dutch version of the Symptom Checklist (SCL-90)]. Nederlands Tijdschrift voor de Psychologie 36, 77-108.

Bartrop, R.W., Luckhurst, E., Lazarus, L., Kiloh, L.G., Penny, R., 1977. Depressed lymphocyte function after bereavement. Lancet $1,834-836$.

Birmaher, B., Rabin, B.S., Garcia, M.R., Jain, U., Whiteside, T.L., Williamson, D.E., Al-Shabbout, M., Nelson, B.C., Dahl, R.E., Ryan, N.D., 1994. Cellular immunity in depressed, conduct disorder, and normal adolescents: role of adverse life events. Journal of the American Academy of Child and Adolescent Psychiatry 33, 671-678.

Cleiren, M.P.H.D., 1993. Bereavement and Adaptation: a Comparative Study of the Aftermath of Death. Taylor and Francis, Washington, D.C.

Fawzy, F.I., Kemeny, M.E., Fawzy, N.W., Elashoff, R., Morton, D., Cousins, N., Fahey, J.L., 1990. A structured psychiatric intervention for cancer patients. II: Changes over time in immunological measures. Archives of General Psychiatry 47, 729-735.

Goodkin, K., Blaney, N.T., Feaster, D., Fletcher, M.A., Baum, M.K., Mantero-Atienza, E., Klimas, N., Millon, C., Szapocnik, J., Eisdorfer, C., 1992. Active coping style is associated with natural killer ccll cytotoxicity in asymptomatic IIIV-1 seropositive homosexual men. Journal of Psychosomatic Research 36, 635-650.

Goodkin, K., Feaster, D.J., Tuttle, R., Blaney, N.T., Kumar, M., Baum, M.K., Shapshak, P., Fletcher, M.A., 1996. Bereavement is associated with time-dependent decrements in cellular immune function in asymptomatic human immunodeficiency virus type 1 -seropositive homosexual men. Clinical and Diagnostic Laboratory Immunology 3, 109-118.

Irwin, M., Daniels, M., Bloom, E.T., Smith, T.L., Weiner, H., 1987a. Life events, depressive symptoms, and immune function. American Journal of Psychiatry 144, 437-441.

Irwin, M., Daniels, M., Smith, T.L., Bloom, E., Weiner, H., 1987b. Impaired natural killer cell activity during bereavement. Brain, Behavior, and Immunity 1, 98-104.

Irwin, M., Daniels, M., Risch, S.C., Bloom, E., Weiner, H., 1988. Plasma cortisol and natural killer cell activity during bcrcavement. Biological Psychiatry 24, 173-178.

Jones, D.R., 1987. Heart disease mortality following widowhood: some results from the OPCS longitudinal study. Journal of Psychosomatic Research 31, 325-333.

Kissane, D.W., Bloch, S., Onghena, P., McKenzie, D.P., Snyder, R.D., Dowe, D.L., 1996. The Melbourne Family Grief 
Study, II: psychosocial morbidity and grief in bereaved families. American Journal of Psychiatry 153, 659-666.

Lehtonen, L., Eskola, J., Lehtonen, A., 1990. Changes in lymphocyte subsets and immune competence in very advanced age. Journal of Gerontology 45, 108-112.

Lieberman, M.A., 1989. Group properties and outcomes: a study of group norms in self-help groups for widows and widowers. International Journal of Group Psychotherapy 39, 191-208.

Lieberman, M.A., Videka-Sherman, L., 1986. The impact of self-help group therapy on the mental health of widows and widowers. American Journal of Orthopsychiatry 56, 435-449.

Lieberman, M.A., Yalom, I., 1992. Brief group psychotherapy for the spousally bereaved: a controlled study. International Journal of Group Psychotherapy 42, 117-132.

Lund, D.A., Caserta, M.S., Dimond, M.F., 1986. Gender differences through two years of bereavement among the elderly. The Gerontologist 26, 314-320.

Lund, D.A., Caserta, M.S., Dimond, M.F., 1989. Impact of spousal bereavement on the subjective well-being of older adults. In: Lund, D.A. (Ed.), Older Bereaved Spouses: Research with Practical Implications. Hemisphere Publishing Corporation, New York, pp. 3-16.

Maes, M., Stevens, W., Peeters, D., DeClerck, L., Scharpé, S., Bridts, C., Schotte, C., Cosyns, P., 1992. A study on the blunted natural killer cell activity in severely depressed patients. Sciences 50, 505-513.

Marmar, C.R., Horowitz, M.J., Weiss, D.S., Wilner, N.R., Kaltreider, N.B., 1988. A controlled trial of brief psychotherapy and mutual-help group treatment of conjugal bereavement. American Journal of Psychiatry 145, 203-209.

McCrae, R.R., Costa, P.T., 1988. Psychological resilience among widowed men and women. Journal of Social Issues 44, 129-142.

Mendes de Leon, C.F., Kasl, S., Jacobs, S., 1994. A prospective study of widowhood and changes in symptoms of depression in a community sample of the elderly. Psychological Medicine 24, 613-624.

Miller, A.H., Asnis, G.M., Lackner, C., Halbreich, U., Norin, A.J., 1991. Depression, natural killer cell activity, and cortisol secretion. Biological Psychiatry 29, 878-886.

Mor, V., McHorney, C., Sherwood, S., 1986. Secondary morbidity among the recently bereaved. American Journal of Psychiatry 143, 158-163.

Murrell, S.A., Himmelfarb, S., Phifer, J.F., 1988. Effects of bereavement/loss and pre-event status on subsequent physical health in older adults. International Journal of Aging and Human Development 27, 89-179.

Nerozzi, D., Santoni, A., Bersani, G., Magnani, A., Bressan, A., Pasini, A., Antonozzi, I., Frajese, G., 1989. Reduced natural killer cell activity in major depression: neuroendocrine implications. Psychoneuroimmunology 14, 295-301.

Parkes, C.M., 1975. Determinants of outcome following bereavement. Omega 6, 303-323.

Parkes, C.M., 1981. Evaluation of a bereavement service. Journal of Preventive Psychiatry 1, 179-188.
Parkes, C.M., Brown, R., 1972. Health after bereavement: a controlled study of young Boston widows and widowers. Psychosomatic Medicine 34, 449-461.

Parkes, M.C., Weiss, R.S., 1983. Recovery from Bereavement. Basic Books, New York.

Pekelharing, J.H. (Ed.), 1995. Handboek Klinisch-Chemische Tests. Wetenschappelijke uitgeverij Bunge Utrecht, pp. 161-285.

Pettingale, K.W., Hussein, M., Tee, D.E.H., 1994. Changes in immune status following conjugal bereavement. Stress Medicine 10, 145-150.

Quarmby, D., 1993. Peer counselling with bereaved adolescents. British Journal of Guidance and Counselling 21, 196-211.

Range, L.M., Niss, N.M., 1990. Long-term bereavement from suicide, homicide, accidents and natural deaths. Death Studies 14, 423-433.

Raphael, B., 1977. Preventive intervention with the recently bereaved. Archives of General Psychiatry 34, 1450-1454.

Raphael, B,, 1980. A psychiatric model for bereavement counseling. In: Bereavement Counseling, a Multidiciplinary Handbook, Greenwood Press, London, pp. 147-172.

Raphael, B., 1983. The Anatomy of Bereavement. Basic Books, New York.

Rodin, J., Salovey, P., 1989. Aging and health: effects of the sense of control. Annual Review of Psychology 40, 533-579.

Sansoni, P., Cossarizza, A., Brianti, V., Fagnoni, F., Snelli, G., Monti, D., Marcato, A., Passeri, G., Ortolani, C., Forti, E., et al., 1993. Lymphocyte subsets and natural killer cell activity in healthy old people and centenarians. Blood 82, 2767-2773.

Schaefer, C., Quesenberry, C.P., Jr., Wi, S., 1995. Mortality following conjugal bereavement and the effects of a shared environment. American Journal of Epidemiology 141, 1142-1152

Schleifer, S.J., Keller, S.E., Camerino, M., Thornton, J.C., Stein, M., 1983. Suppression of lymphocyte stimulation following bereavement. JAMA 250, 374-377.

Schleifer, S.J., Keller, S.E., Bond, R.N., Cohen, J., Stein, M., 1989. Major depressive disorder and immunity: role of age, sex, severity and hospitalization. Archives of Gencral Psychiatry $46,81-87$.

Schut, H.A.W., 1992. Omgaan met de dood van de partner: effecten op gezondheid en effecten van rouwtherapie [Coping with conjugal bereavement: effects on psychological functioning and effects of grief counselling]. Thesis Publishers, Amsterdam.

Seidel, A., Arolt, V., Hunstiger, M., Rink, L., Behnisch, A., Kirchner, H., 1996. Increased $\mathrm{CD}^{+} 6^{+}$natural killer cells and related cytokines in major depression. Clinical Immunology and Immunopathology 78, 83-85.

Spurrell, M.T., Creed, F.H., 1993. Lymphocyte response in depressed patients and subjects anticipating bereavement. British Journal of Psychiatry 162, 60-64.

Stein, M., Miller, A.H., Trestman, R.L., 1991. Depression, the immune system, and health and illness. Findings in search of meaning. Archives of General Psychiatry 48, 171-177. 
Stroebe, M., Stroebe, W., 1991. Does 'grief work' work? Journal of Consulting and Clinical Psychology 59, 479-482.

Taylor, S.E., 1990. Health psychology: the science and the field. American Psychologist 45, 40-49.

Urch, A., Muller, C., Aschauer, H., Resch, F., Zielinski, C.C., 1988. Lytic effector cell function in schizophrenia and depression. Journal of Neuroimmunology 18, 291-301.

Vachon, M.L., Sheldon, A.R., Lancee, W.J., Lyall, W.A.L., Rogers, J., Freeman, S.J.J., 1980. A controlled study of self-help interventions for widowers. American Journal of Psychiatry 137, 1380-1384.

Yalom, I.D., Lieberman, M.A., 1991. Bereavement and heightened existential awareness. Psychiatry 54, 334-345.

Yalom, I.D., Vinogradov, S., 1988. Bereavement groups: techniques and themes. International Journal of Group Psychotherapy $38,419-446$.
Zisook, S., Schuchter, S.R., 1991. Depression through the first year after the death of a spouse. American Journal of Psychiatry 148, 1346-1352.

Zisook, S., Schuchter, S.R., 1993. Uncomplicated bereavement. Journal of Clinical Psychiatry 54, 365-372.

Zisook, S., Schuchter, S.R., Sledge, P.A., Paulus, M., Judd, L.L., 1994a. The spectrum of depressive phenomena after spousal bereavement. Journal of Clinical Psychiatry 55, 29-36.

Zisook, S., Schuchter, S.R., Irwin, M., Darko, D.F., Sledge, P., Resovski, K., 1994b. Bereavement, depression and immune function. Psychiatry Research 52, 1-10.

Zisook, S., Schneider, D., Schuchter, S.R., 1990. Anxiety and bereavement (review). Psychiatric Medecine 8, 83-96. 